\title{
Análisis de la película Custodia compartida
}

\author{
Film analysis Shared custody
}

AidA OLIETE LEÓN

Licenciada en Derecho en la Universidad de Oviedo

Recibido: $17 / 9 / 2019$

Aceptado: $15 / 10 / 2019$

doi: https://doi.org/10.20318/femeris.2020.5163

Resumen. En este artículo analizo la película Custodia compartida, a través del mismo quiero explicar todos aquellos problemas que la cinta muestra de modo más o menos sutil, entre ellos, lo peligroso y pernicioso que es obviar el carácter violento y agresivo de un hombre que ha mostrado ser violento con sus hijos y su ex mujer, lo peligroso que muchas veces es rechazar las declaraciones de los hijos en situaciones como la que esta película muestra. Parece mentira, pero a día de hoy todavía debemos recordar que un maltratador no puede ser un buen padre y que por lo tanto todos tendríamos que ser conscientes de lo mucho que pueden llegar a sufrir los menores que se encuentren bajo su tutela, pasar tiempo con un hombre agresivo e inestable que ya ha tenido malos comportamientos con sus hijos y cuyas actitudes han hecho que desarrollen un miedo más que justificado hacia él no puede ser considerado un hecho poco relevante por parte de quienes defienden el interés supremo del menor. Es muy importante estudiar cada caso de forma separada y no aplicar el mismo criterio de forma general, estoy segura de que esto no se hace en la mayoría de las ocasiones, pero aun así, este tipo de historias nos hacen reflexionar.

Palabras clave: Ley, sociedad, machismo, padre, madre..

Abstract. In this article I analyze the movie "Custodia compartida", through it I want to explain all those problems that the film shows in a more or less subtle way, among them, how dangerous and pernicious it is to obviate the violent and aggressive character of a man who has shown being violent with his children and his wife, the dangerous thing that many times is to reject the statements of the children in situations like the one this movie shows. It seems a lie, but today we must still remember that an abuser cannot be a good father and therefore we should all be aware of how many children under his guardianship can suffer, spend time with an aggressive and unstable man who has already had bad behaviors with his children and whose attitudes and behaviors have caused them to develop a more than justified fear towards him cannot be considered a little relevant fact by those who defend the supreme interest of the child. It is very important to study each case separately and not apply the law as a block, I am sure that this is not done on most occasions but still, these types of stories make us reflect.

Keywords: Law, society, sexism, father, mother.

\footnotetext{
*a-oliete@hotmail.com
} 


\section{Introducción}

Antes de analizar esta película me gustaría reflexionar sobre el concepto "violencia de género", desgraciadamente sigue habiendo muchos políticos que ponen en duda o incluso niegan la existencia de esta realidad, es cierto que cualquier persona puede ser agredida o violentada, pero si hay un tipo de ley que se centra en la violencia que sufren las mujeres por parte de los hombres es por una razón, ¿por qué se habla de violencia de género? Muchas personas dicen que antes la vida era mejor, cuando las mujeres se quedaban en casa, pero recuerdo que es eso mismo lo que constituyó la sociedad patriarcal, aquella en la que los hombres, al ser la cara visible de todas las instituciones hacían todo a su medida, desde dictar leyes hasta crear los cimientos de la sociedad, cuando las mujeres solo hacían eso -dedicarse a la casa y sus hijos- toda la sociedad se aferraba a estos estereotipos, las mujeres debían quedarse en casa, ser obedientes, sumisas, cariñosas, la mujer tenía que cuidar de sus hijos para que todo fuese bien, hace años era lo que todas ( o al menos la gran mayoría) hacía, de puertas hacia fuera parecía que todo estaba bien, pero cuando las mujeres no tienen voz ni voto en el mundo, los estereotipos de género demuestran toda su toxicidad, los hombres son los fuertes, los que proveen, los que mandan, las mujeres son débiles y frágiles, y no tiene sentido que aspiren a lo mismo a lo que un hombre puede aspirar, eran ellos quienes en esa época y aun en esta (en muchos países) se creían con derecho a corregirlas si no se comportaban como una mujer se debía comportar, recuerdo una frase de Chimanda Ngozi Adichie "Enséñale a tu hija que los "roles de género" son una solemne tontería. No le digas nunca que debe hacer algo o dejar de hacerlo "porque es una niña". "Porque eres una niña" nunca es una razón para nada"1 ... también añadía "Mi amigo Nwabu una vez me contó que, como su mujer lo dejó cuando los niños eran pequeños, él se convirtió en el Sr Mamá, con lo que quería decir que se encargaba de los cuidados diarios. Pero no estaba ejerciendo de Sr Mamá, simplemente hacía de padre"2, escuchar esto me hizo comprender por qué nunca me había llamado la atención la frase mujer trabajadora, madre trabajadora o mujer fuerte, si hay algo que disminuye la violencia de cualquier colectivo es su visibilidad, su integración en la sociedad, las mujeres somos personas, no somos cuerpos, no somos meras sirvientas, no somos las hijas, mujeres o hermanas de ... son los estereotipos machistas que aún existen los que consideran que los hombres, por el hecho de ser hombres pueden decirle a sus mujeres lo que deben o no deben hacer, los que tienen que dominar la relación y los que en algunos casos, lamentablemente no creen hacer nada extraño si se comportan así. En esta película se muestra el miedo que unos hijos pueden sentir por su padre, el motivo por el que esta situación no debería pasar desapercibida.

\footnotetext{
${ }^{1}$ CHIMAMANDA NGOZI ADICHIE. (2017) Querida Ijeawele, o cómo eduar en el feminismo: Dear Ijeawele Or A Feminist Manifesto In Fifteen. Estados Unidos. Alfred A Knopf.

${ }^{2}$ CHIMAMANDA NGOZI ADICHIE. (2017) Querida Ijeawele, o cómo eduar en el feminismo: Dear Ijeawele Or A Feminist Manifesto In Fifteen. Estados Unidos. Alfred A Knopf.
} 


\section{Custodia compartida}

A veces quienes creen que no puede haber nada más allá de la ley no se dan cuenta de que ésta tiene la obligación de proteger a la sociedad, la ley puede ser injusta, puede tratar ciertos casos de una forma tan generalizada que en lugar de garantizar el mismo tipo de resoluciones estaría promoviendo una más que previsible arbitrariedad.

El testimonio de un niño pequeño, como ocurre en esta película, sigue sin tener demasiado valor, los niños y niñas pueden ser examinados, si una persona cree que están mintiendo o manipulando tal vez un psicólogo nos podría hacer entender la realidad.

No es normal que un niño sienta terror por su padre, una jueza como la de esta película, en su empeño por finiquitar un caso que podría alargarse más, decide omitir las explicaciones de los hijos y el más que evidente temor de la ex mujer para aplicar una ley que, al menos en este caso, no vela por el interés del menor.

En esta película se ve a una mujer triste, una madre sin autoestima, cansada de luchar, dispuesta ceder para evitar un mal que saber mayor, el padre, que no se controla, no ha dado las muestras que la jueza consideraba necesarias para ser apartado del hijo que tanto miedo tiene a volverle a ver. Un niño atemorizado, una niña con una lesión causada por su padre y una mujer que ha dejado de sentirse segura en su propia casa no suponen elementos suficientes para que la jueza entienda que, en esa familia, hay un problema que necesita una consideración especial. ¿Qué más pruebas se necesitan? Puede haber informes psiquiátricos, test psicológicos, testigos ... siempre hay algo que se puede hacer para proteger a un niño pequeño, que, muerto de angustia, tiene miedo de sufrir.

La realidad es implacable, desde hace años se cuentan por decenas los niños que han sido asesinados por un padre vengativo, los niños y niñas que han quedado huérfanos por la misma razón, la custodia compartida no siempre es la solución, cada caso debería ser examinado de manera minuciosa, y en mi opinión, hay ciertas situaciones que no se pueden ignorar.

El padre sabe que su ex mujer no le quiere volver a ver, sin embargo, utiliza el miedo que su hijo le tiene para hacer que la madre vuelva a acercarse a él, la acecha allá donde está, trata de interrogarla e inmiscuirse en todos aquellos asuntos que ya solo forman parte de su propia intimidad.

Cada vez que están solos, el hijo acaba llorando, sintiéndose controlado y manejado por un hombre del que no puede escapar. La madre quiere protegerlo, pero no puede oponerse a lo dictado por la ley.

No entiende a su hijo, cree que tanto él como su ex mujer deben ceder a sus exigencias y está seguro de que no deberían negarse a nada de lo que les quiera pedir, de alguna forma está acostumbrado a manejarse utilizando las amenazas y la intimidación y cuando esta no funciona no tiene reparos en ir más allá. En algunas escenas entendemos la tensión que soportan los protagonistas, incluso los padres del protagonista comprenden el motivo por el que lo dejó su ex mujer.

Cuando entra en la casa para conocer el lugar en el que están viviendo, tanto su ex mujer como su hijo quieren que se vaya de ahí, el espectador lo sabe y la tensión se hace 
más insoportable a cada momento, el padre lo puede percibir, pero sabe que cuenta con el miedo que le tienen y se aprovecha de esa situación.

El ambiente resulta sofocante y en la mayoría de las ocasiones es el padre quien genera esa tensión, parece que a su hijo solo que queda someterse y obedecer, si su ex mujer no quería que supiera donde viviese, estamos ante un detalle que cualquier juez de familia tendría que hacer el esfuerzo de considerar. En realidad no es una cuestión de esfuerzos, el padre utiliza a su hijo, y aunque sus abuelos lo saben, no hay muchas cosas que ellos puedan hacer, los detalles son mucho más importantes que el dialogo, hay cosas que a ninguno de los personajes les resulta necesario mencionar, los silencios son más elocuentes que las palabras que se atreven a decir, y cuando la hija canta en su cumpleaños, su gesto de profunda preocupación desentona por completo con el ritmo de una canción que seguramente le apetecía dejar de cantar.

El final de la película es como una especie de catarsis, sabíamos que iba a pasar algo, pero como ocurre muchas veces las muestras de violencia que dio el padre no fueron tomadas en consideración ni evitaron, lo que, a lo largo de la película nos íbamos imaginando que podría suceder.

La tensión se maneja de una forma bastante sutil, de este modo los personajes interactuando de un modo natural, del modo en que lo harían sin que lo obvio tenga que mostrarse como tal, sin decir ni hacer nada que cualquier espectador no pueda llegar a intuir, el personaje principal muestra la personalidad de quien, en lugar de hacer ver su verdadera naturaleza, tiene demasiado que ocultar, cualquier otra pose resultaría falsa o exagerada, a veces, las cosas no son tan claras como se muestran en la escena final, para llegar hasta ese momento tiene que darse varias situaciones que muchas personas, en su intento de justificar lo injustificable intentan obviar.

La violencia puede ser muy peligrosa si se ejerce de un modo sutil, y es así como va escalando hasta convertirse en una realidad de la que ya es mucho más difícil escapar.

Del carácter de la madre se intuye que está cansada de luchar, que sabe que ninguna de sus preocupaciones será tomada en consideración, es posible que la jueza exigiera muestras claras de violencia, y hay situaciones que por desgracia no se pueden denunciar, si no hay testigos, si el golpe no deja marcas, si en caso contrario pasa el tiempo suficiente como para que la víctima se decida a denunciar... si no ocurre algo más evidente, parece que muchas veces, tenemos que seguir esperando a que suceda algo mucho peor.

La última escena es triste, afortunadamente el padre es detenido, pero el trauma del hijo persistirá, al final una vecina se involucra y llama a la policía, pero esto muchas veces no ocurría así, las peleas o la violencia intrafamiliar se consideraba un asunto privado y había gente que no se creía con el derecho a intervenir, hoy en día las cosas han cambiado y lo que ocurre dentro de una pareja, en el caso de que haya violencia, ya no es solo cosa de dos. Si se vulneran los derechos de una persona, si conocemos que se está maltratando a una persona, todos estamos jurídica y moralmente obligados a intervenir, no tenemos que jugarnos la vida para proteger a nadie, pero mirar hacia otro lado no nos convertirá en una sociedad mejor. 
Hay muchas cosas que tenemos que intuir, lo que pudo suceder durante el matrimonio, que vio o sufrió el hijo para temer a un padre, que, en un primer momento no parece violento con él, qué pasó con los abuelos para que, sin atreverse a manifestarse, se muestren favorables a su ex mujer, ellos mismos hablaban de su hijo con si simplemente tuviera mal carácter, pero todos sabemos que se tratar de algo más.

No se sabe si la juez se dejó llevar por la literalidad de la ley o no quiso empatizar con unos padres a los que no se había tomado la molestia de conocer, a veces damos por hechos que las personas adultas se tienen que dejar llevar por la lógica y el sentido común, en este caso, como ocurre en todos, son las personas adultas quienes que tienen que velar por la situación del menor, si la jueza, que no parece muy interesada en ver más allá de lo presentado por las partes, no es capaz de hacer nada más solo podemos imaginarnos que en circunstancias como estas, serán muchos los jueces de familia que, agobiados por la dilación de casos interminables, opten por actuar fríamente y se olviden de esas situaciones latentes, que no son ni más ni menos, lo que todo sistema justo tendría que esforzarse por encontrar.

Esta película es realmente buena, emotiva sin caer en el sentimentalismo, realista sin mostrar una crudeza más turbia de la que la mayoría de los espectadores pudiésemos imaginar.

Todas las personas que se dedican al derecho la tendrían que ver, quizá no aprendiesen nada nuevo y estuviesen totalmente de acuerdo con su proyección, pero a veces no nos damos cuenta de que una aplicación mecánica y distante puede hacer tanto daño como su completa omisión, si no piensan que cada caso merece una atención personalizada corren el riesgo de cometer errores que pueden desembocar en consecuencias graves e incluso a veces irreparables.

Después de ver esta película me acorde de otra (no matarás) en la que un chico es condenado a muerte por un juez que, según sus propias palabras, no hubiera podido hacer otra cosa, ni dictar una sentencia mejor. La ley es imperativa pero no coarta por completo la libertad del juez. Las circunscritas son importantes y son las que deben llevarnos a pensar.

Las circunstancias son esenciales, y tal vez, como se muestra en varias películas, los funcionarios, y todas las personas que ejercemos cualquier tipo de profesión olvidamos que algunas decisiones tienen más transcendencia de la que muchas veces podemos intuir.

Hay situaciones que en un primer momento no somos capaces de prever, sin embargo, si queremos evitar un mal mayor, debemos hacer caso de esos avisos que la mayoría de las veces se presentan con una clara intención.

El miedo puede ser ilógico, pero en estos casos los jueces deberían hacerse cargo de las situaciones en las que las partes se contrapongan y se ponga en juego el interés del menor.

\section{Conclusión}

Teniendo en cuenta todo lo expuesto y la temática de la película, hay una cosa que deberíamos tomar en consideración, es cierto que cualquier persona puede ejercer la violencia, sin embargo, aunque todas las víctimas de la misma merecen protección, y por lo 
tanto, toda persona que la ejerza un castigo, no debemos olvidar que si la violencia de genero recibe este nombre es porque, como muchos estudios psicólogos y sociológicos demuestran el maltratador suele tener una mentalidad machista, un afán de dominación y posesión propios de los hombres que consideran que una mujer tiene que someterse a ciertas normas de las que ellos parecen estar exentos, la mentalidad machista fomenta la violencia, y los hombres que se aferran a estos prejuicios y estereotipos no tendrán relaciones sanas y basadas en la igualdad, es obvio que no todos los hombres son malos ni agresivos, quiero pensar que la enorme mayoría está en contra de la violencia contra la mujer, pero para lograr erradicar esta lacra debemos ser conscientes de su origen, y el origen de la violencia en casos como el de esta película y otras como Te doy mis ojos o Solo mía, está en el pensamiento de un hombre machista, posesivo y controlador.

\section{Referencias bibliográficas}

CHIMAMANDA NGOZI ADICHIE. (2017) Querida Ijeawele, o cómo eduar en el feminismo: Dear Ijeawele Or A Feminist Manifesto In Fifteen. Estados Unidos: Alfred A Knopf. 